Article

\title{
Experimental Study on the Fire Resistance Performance of Partition Board under the Condition of Small Fire Source
}

\author{
Butong Gao ${ }^{1}$, Shanyang Wei ${ }^{1, * \mathbb{D}}$, Wei Du ${ }^{2}$, Huan Yang ${ }^{3}$ and Yunyun Chu ${ }^{1}$ \\ 1 Mining College, Guizhou University, Guiyang 550025, China; gaobutong1998@gmail.com (B.G.); \\ chuyunyun4@gmail.com (Y.C.) \\ 2 State Grid General Aviation Company Limited, Beijing 102209, China; du-wei@sgga.sgcc.com.cn \\ 3 China Construction Fourth Division Guizhou Investment and Construction Co., Ltd., Guiyang 550081, China; \\ yanghuan9609@gmail.com \\ * Correspondence: sywei1@gzu.edu.cn; Tel.: +86-185-8690-4696
}

Citation: Gao, B.; Wei, S.; Du, W.;

Yang, H.; Chu, Y. Experimental Study on the Fire Resistance Performance of Partition Board under the Condition of Small Fire Source. Processes 2021, 9 , 1818. https://doi.org/10.3390/ pr9101818

Academic Editor: Titan C. Paul

Received: 11 August 2021

Accepted: 9 October 2021

Published: 13 October 2021

Publisher's Note: MDPI stays neutral with regard to jurisdictional claims in published maps and institutional affiliations.

Copyright: (C) 2021 by the authors. Licensee MDPI, Basel, Switzerland. This article is an open access article distributed under the terms and conditions of the Creative Commons Attribution (CC BY) license (https:// creativecommons.org/licenses/by/ $4.0 /)$.

\begin{abstract}
Fire safety of ancient wooden buildings is one of the most important issues in the world. In this paper, partition boards with different thicknesses from 15 to $25 \mathrm{~mm}$ were heated by a $15-\mathrm{cm}$ diameter pool fire and a methane Bunsen burner. The temperatures and the carbonization rate of partition boards were measured and analyzed. The results show that when a pool fire was used to heat the wood sample at a distance of $30 \mathrm{~cm}$, two flames appear on the sample surface. When a Bunsen burner heats the sample, the sample is burned until the center point is burned through. The thickness of the sample is increased by $5 \mathrm{~mm}$, and the acceleration time of the temperature rise rate at the center is doubled. Under the condition of a pool fire, the thickness of the sample is increased by $5 \mathrm{~mm}$, and the average carbonization rate at the center point is reduced by $40 \%$. Under the condition of Bunsen burner, the average carbonization rate of the center point decreases exponentially when the thickness of the sample increases by $5 \mathrm{~mm}$. In the case of the same fire source, the carbonization rate of the samples with different thicknesses has the same change trend in the horizontal and vertical directions. Compared with the pool fire, the burn-through time of the center point of the sample is reduced in the case of the Bunsen burner for a sample of the same thickness, and the average carbonization rate of each measuring point increases.
\end{abstract}

Keywords: partition board; pool fire; Bunsen burner; surface temperature; carbonization speed

\section{Introduction}

The materials used in ancient buildings are mainly wood, which is different from current reinforced concrete structures. With the development of productivity, there are more and more fire hazards, which lead to a large number of fire accidents. The fire load of ancient wooden buildings is large, and they are more likely to be ignited. Once a fire occurs, it will cause serious economic property losses due to the fast flame propagation speed and the difficulty in fire protection. Therefore, it is important to conduct fire resistance tests of ancient wood buildings.

There has been some research on the fire resistance of wood structures. Lau et al. [1], Spearpoint et al. [2], Frangi et al. [3], and Janssens et al. [4] found that combustible volatile substances will be produced from wood when it is burned and decomposed, which further promotes the thermal decomposition of wood. Van et al. [5] and Hofmann et al. [6] carried out fire experiments of wooden load-bearing components. From the surface to the interior, the sample can be divided into carbonization layer, carbonization base layer, high-temperature decomposition zone, high-temperature decomposition base zone, and normal zone [7]. Thomas [8] studied the tensile and compressive strength of the wood column after it completely burned out by first measuring the various data of the wooden column under a standard flame, and then using software that simulated the burning of wooden pillars under natural fire, and the results showed that the wood is prone to 
destroy when the wood is heated delayed and the wood is hotter at a lower temperature. Zhang et al. [9] proposed a Bayesian numerical model based on the total weight change of wood in the process of moisture transfer to calculate the moisture emission factor on the surface of small-sized wood and, finally, determined the emission factor under surface moisture. Danica et al. [10] heated the samples at three temperatures to determine the change of lignin in the samples and the change mode to improve the stability and heat resistance of the wood. After the wood is burned by the flame, the wood surface will form a carbonization layer, whose carbonization rate is determined by the moisture content and density of the wood [11]. Schnabl et al. [12] conducted experimental research on wooden pillars with different moisture content and found that the higher the moisture content of the wooden pillar, the lower the temperature at the same location under the same burn time. Ali and Kavanaugh [13] conducted a four-sided fire test on eight glulam columns under axial compression. The results showed that the fire resistance limit of glulam columns decreased significantly with the increase of load-holding conditions and also decreased with the increase of slenderness ratio. Park et al. [14] performed a cone calorimeter test on laminated plywood samples with multiple grain orientations and performed a fullscale fire resistance test on large-section laminated plywood beams (without connections) in a large furnace to determine the carbonization rate of the laminate and the plywood. Frangi et al. [15] conducted a single-sided fire test of five different plywoods and found that the fire performance of the plywood has a greater relationship with the glue type. The better the fire resistance of the glue, the better the fire resistance of the plywood. Babrauskas [16] conducted a fire test study of a full-scale wooden structure. The study found that the carbonization rate of each component in a full-scale wooden structure is related to the initial defects of the components, the layout position, the characteristics of the house, the ventilation conditions, and the location of the components. Blondin et al. [17] selected three kinds of compressed straws with densities of 75,125 , and $175 \mathrm{~kg} / \mathrm{m}^{3}$. They were subjected to combustion tests at different scales and compared with non-combustible insulating materials; the results show that compressed straw with a density of $75 \mathrm{~kg} / \mathrm{m}^{3}$ has the best fire resistance. Rabe et al. [18] applied methanol solution, acetylation, and heat treatment to the wood and compared it with the untreated wood, the treated wood had better flame retardant performance. Suoware et al. [19] studied the sawdust fire response of material, using a universal testing machine, TGA, and cone calorimeter. The tensile properties of materials that added different flame retardant properties were tested in addition to the bending properties and thermal stability, the results indicate that added impurity-free flame retardant material will improve the tensile properties, flexural properties, and fire performance. Meanwhile, the wood was also treated with resin [20], polyethylene [21], ammonium polyphosphate [22], and other flame-retardant materials, and then the flame retardancy was measured. Audouin et al. [23], Koseki et al. [24], Hamins et al. [25], Chatris et al. [26], and Kang et al. [27] studied the radiant heat flux of different pool fire sources. As a prefabricated component in a wooden stilt building, the partition board not only serves as a blocking function for each room, but to a certain extent, it can prevent the spread of flames inside the building. Small-size fire source combustion is mainly used to study and analyze the fire hazard and flame retardancy of materials. The UL94 vertical combustion test is applied to study the combustion performance of materials under the action of small-scale fire source combustion [28,29], the UL94 test uses a Bunsen burner $[30,31]$ as a small fire source to analyze the characteristics of the combustion behavior of small-sized polymers under the action of a small fire source. However, so far, there are few studies on the combustion characteristics of wood structure building components under the effect of small-scale fire sources.

In this paper, a 15-cm-diameter pool fire and a methane Bunsen burner were used to burn the partition board of wooden buildings, and the combustion characteristics under different conditions were investigated to reveal the fire resistance performance of wooden buildings. 


\section{Experimental Setup}

In order to make the test results closer to the actual situation, the partition boards were made of pine glulam from local wooden buildings. The density of the partition boards was $453.7 \mathrm{~kg} / \mathrm{m}^{3}$, the moisture content was $14.6 \%$, and the size was $500 \times 500 \mathrm{~mm}$. The specific parameters of the materials are listed in Table 1.

Table 1. Specific parameters of partition boards.

\begin{tabular}{|c|c|c|c|c|}
\hline Sample & $\begin{array}{l}\text { Sample } \\
\text { Number }\end{array}$ & Materials & Fire Source & $\begin{array}{l}\text { Size of Partition } \\
\text { Boards (mm) }\end{array}$ \\
\hline \multirow{5}{*}{ Partition board } & A-20 & & \multirow{2}{*}{ 15-cm-diameter pool fire } & $500 \times 500 \times 20$ \\
\hline & A-25 & & & $500 \times 500 \times 25$ \\
\hline & B-15 & Pine glulam & \multirow{3}{*}{ Methane Bunsen burner } & $500 \times 500 \times 15$ \\
\hline & B-20 & & & $500 \times 500 \times 20$ \\
\hline & B-25 & & & $500 \times 500 \times 25$ \\
\hline
\end{tabular}

The pool fire used industrial alcohol as fuel. The diameter of the pool was $15 \mathrm{~cm}$, the height of the pool was $50 \mathrm{~mm}$. The pool was filled with alcohol. The temperature change at $30-60 \mathrm{~cm}$ above the pool fire is shown in Figure 1. According to Figure 1 and reference [32], the partition boards were placed at a height of $30 \mathrm{~cm}$ above the pool fire during the experiments, where the temperature was stable at $270{ }^{\circ} \mathrm{C}$. The flame of the Bunsen burner was produced by a mixture of methane and air. The most distinguishing feature of the Bunsen burner was high temperature but low heat radiation. The partition boards were placed at $60^{\circ}$ from the horizontal [33], and the nozzle of burner was kept perpendicular to the sample plane. The distance from the Bunsen burner nozzle to the sample was $100 \mathrm{~mm}$. According to the literature [34], the selection of sample, the calculation of carbonization rate and the calculation of carbonization speed were determined. The relative positions of the boards and both fire sources are presented in Figure 2.

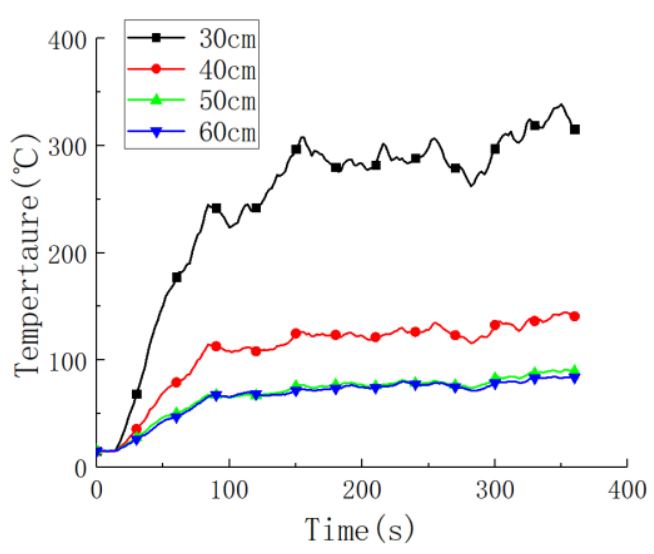

Figure 1. The temperature of the pool fire at different heights.

In order to study the surface temperature of the sample during the burning process by pool fire and Bunsen burner, a series of K-type thermocouples were arranged on the back of the wood board as shown in Figure 3. The diameter of the K-type thermocouple was $6 \mathrm{~mm}$, and it was fixed on the surface of the sample with pins. Among them, TC 1 was arranged at the center of the partition board, and the other points were evenly arranged in the four directions. The interval length between adjacent points was $100 \mathrm{~mm}$.

The experiments were stopped when the partition boards were burnt through by fire sources. At the same time, the carbonated thickness and the residual unburned thickness at measurement points were recorded to calculate the carbonization rate. 


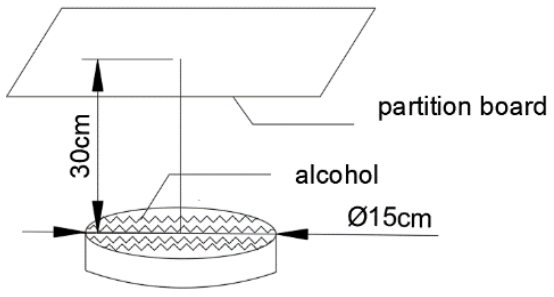

(a)

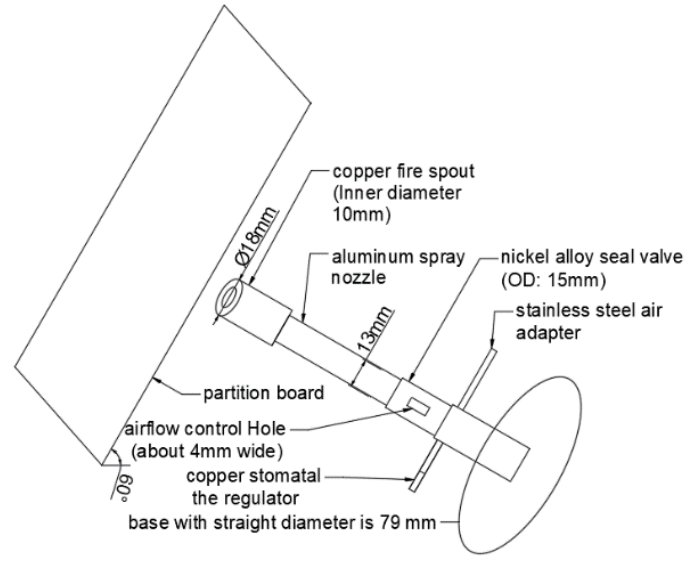

(b)

Figure 2. Structural diagram of partition boards and both fire sources. (a) Pool fire; (b) Bunsen burner.

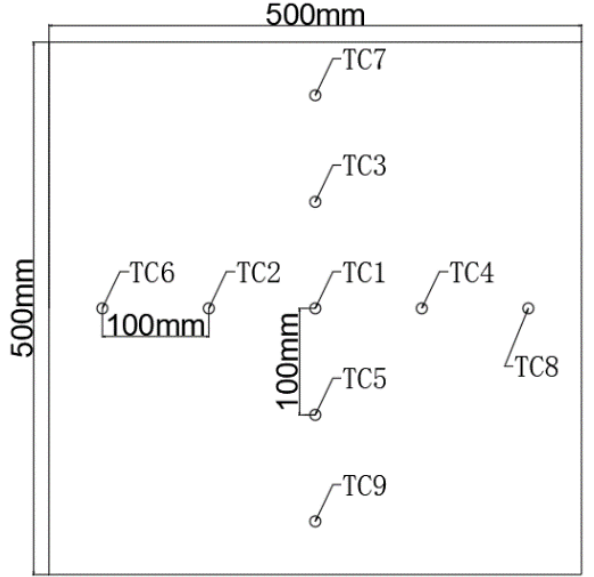

(a)

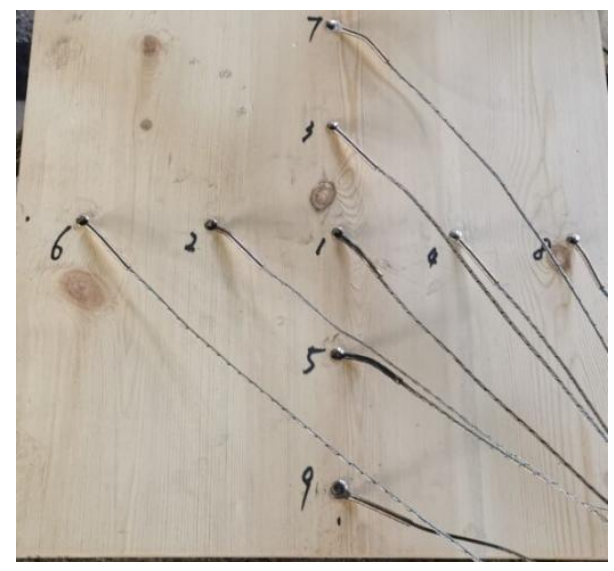

(b)

Figure 3. Thermocouple layout of partition board sample. (a) Schematic diagram of partition board sample; (b) The physical map of the partition board sample.

\section{Results and Analysis}

\subsection{Combustion Phenomenon of Partition Boards}

For sample number A-20, the surface of the sample was thermally decomposed to produce combustible volatile gas. When the sample was exposed to fire for $272 \mathrm{~s}$, the sample wood was thermally decomposing under the action of the fire source, releasing combustible gas, and the fire source ignited the combustible gas on the surface of the sample. When the sample was exposed to fire for $295 \mathrm{~s}$, the surface of the sample wood board burned violently, the sound of an explosion was heard, the wood board sample began to deform, and the surface of the sample showed convex curvature. As the burning surface was further carbonized, the thermal decomposition rate decreased, and the flame on the surface of the sample decreased gradually. When the sample was exposed to fire for $312 \mathrm{~s}$, the combustible gas released by the thermal decomposition of the sample burned out, the flame on the surface of the sample went out, and the sample entered a smoldering state. Figure $4 \mathrm{c}$ shows that the combustible gas was decomposing from the sample and was ignited by the effect of high temperature, which produced flame on the surface of the sample. Figure $4 \mathrm{~d}$ implies that the combustible gas burnt out, and the flame on the surface of the sample was gradually extinguishing. Figure $4 \mathrm{e}$ indicates the reignition of samples resulted from the combustion of the board itself. When the sample was exposed 
to fire for $635 \mathrm{~s}$, the sample burned due to the continuous fire, and the fire on the surface of the sample was reignited, and flames appeared on the surface of the sample. As the test time increased, the sample crackled and became severely deformed. When the sample was exposed to fire for $1050 \mathrm{~s}$, the flame on the surface of the sample was extinguished again, and the sample smoldered until the end of the test. The fire situation of the sample is shown in Figure 4.

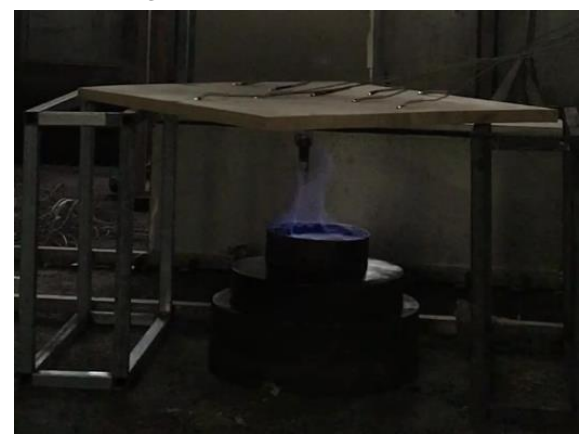

(a)

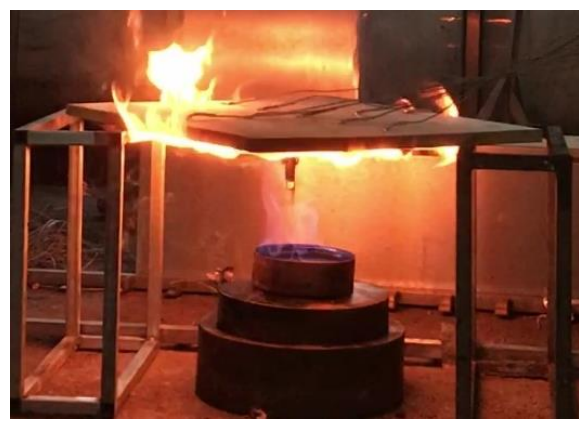

(c)

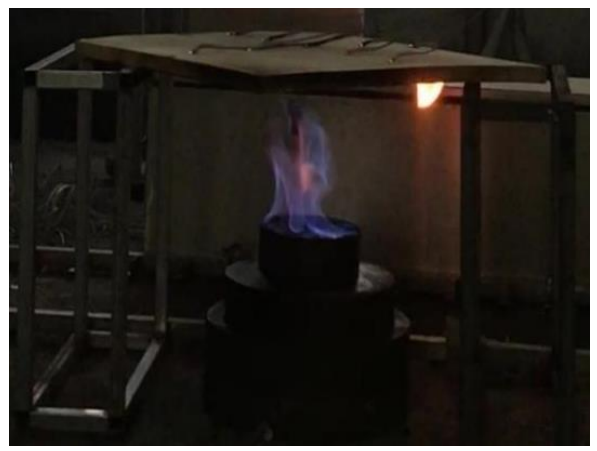

(e)

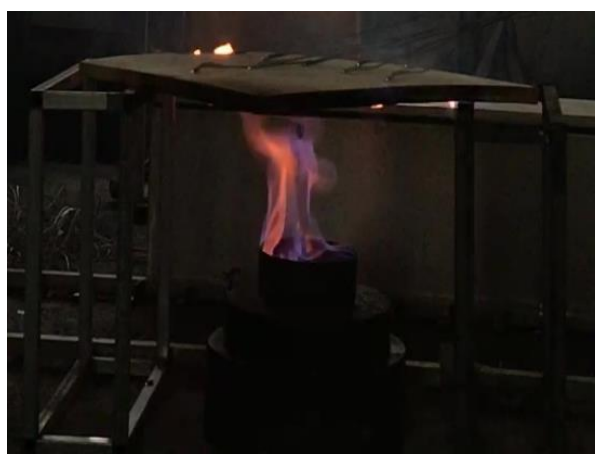

(g)

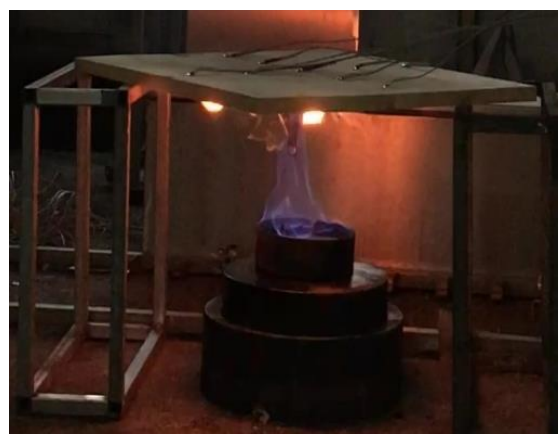

(b)

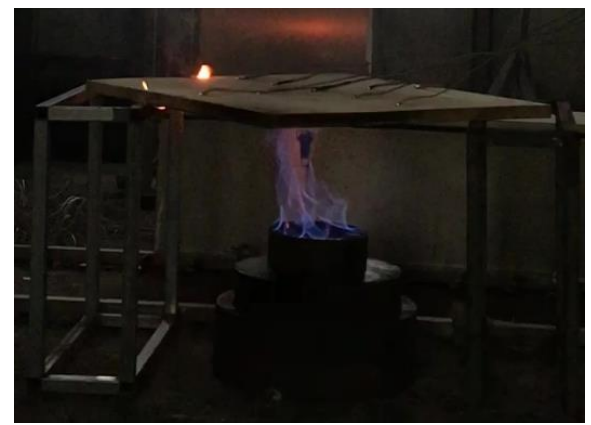

(d)

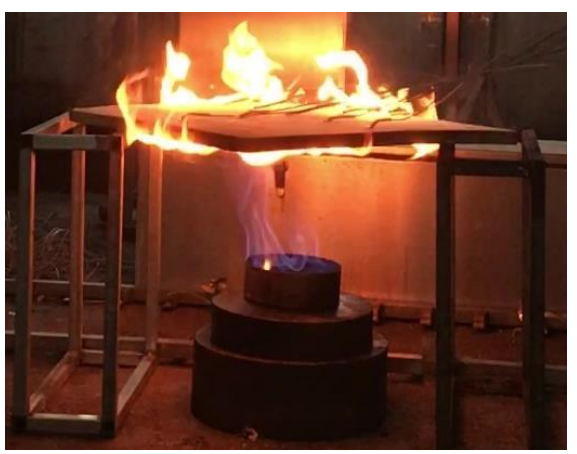

(f)

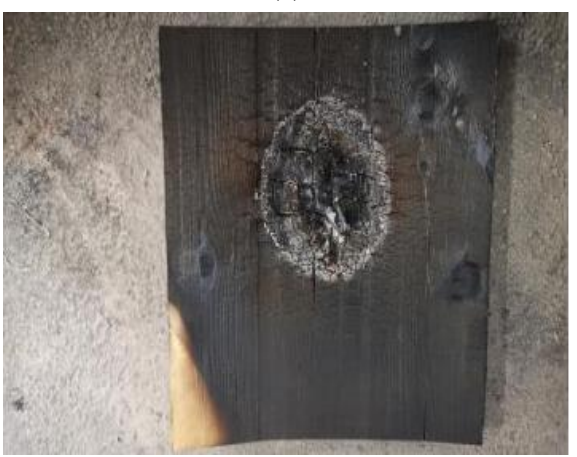

(h)

Figure 4. Combustion of sample A-20. (a) $5 \mathrm{~s}$; (b) $272 \mathrm{~s}$; (c) $295 \mathrm{~s}$; (d) $312 \mathrm{~s}$; (e) $635 \mathrm{~s}$; (f) $766 \mathrm{~s}$; (g) $1050 \mathrm{~s}$; (h) Condition after sample test. 
For sample number A-25, when the sample was exposed to fire for $298 \mathrm{~s}$, the flammable gas released by the thermal decomposition of the sample was ignited and caused a flame on the surface of the sample. At the same time the sample deformed accompanied by a detonation sound. When the sample was exposed to fire for $480 \mathrm{~s}$, the combustible gas on the surface of the sample burned out, causing the flame to go out, and the sample entered a smoldering state. When the sample was exposed to fire for $1885 \mathrm{~s}$, the surface of the sample was continuously heated, and flames appeared again on the surface of the sample. When the sample was exposed to fire for $1985 \mathrm{~s}$, the flame on the surface of the sample spread from both sides of the sample to the thermocouple arrangement on the back of the sample, causing the temperature at that point to start to rise. When the sample was exposed to fire for $2350 \mathrm{~s}$, the flame on the surface of the sample was extinguished, the sample entered a smoldering state, and the surface of the specimen was severely deformed.

When the partition board was burned under the action of the flame jet of the Bunsen burner, the wood board was at an angle of $60^{\circ}$ with the ground and perpendicular to the jet flame of the Bunsen burner. The flame temperature of the Bunsen burner was relatively high and concentrated. The flame heat radiation of the Bunsen burner was relatively small. The flame of the Bunsen burner mainly burned the center of the sample. After the sample burned for a period of time, the center of the wood and its upper part burned severely. The burning direction of the Bunsen burner was upward, so the lower part of the sample was intact. The sample was not ignited until the center point burned through, and the flame spread to the back of the partition board and spread upward and the test ended. Since the fire source was directly sprayed on the sample by the methane Bunsen burner, the sample did not enter the smoldering state. The test phenomenon of the partition board under the Bunsen burner fire source is shown in Figure 5, taking sample B-20 as an example.

\subsection{Analysis of Sample Temperature Field Changes}

In order to effectively and fully record the temperature change data on the back of the partition board sample during the burning process of the pool fire and the Bunsen burner, the temperature data of the K-type thermocouple were collected every $5 \mathrm{~s}$ during the pool fire and Bunsen burner combustion test of the partition board sample. The specific temperature changes during the test of each sample of the partition boards are shown in Figures 6-10.

According to Figures 6-10, the temperature change of the partition board sample in the 15-cm-diameter pan pool fire and methane Bunsen burner burning fire surface was as follows.

According to Figure 6, when the burn time reached about $750 \mathrm{~s}$, combustible gas was released by the decomposition of the wood board due to heating. The combustible gas was ignited by the fire source, and the surface of the sample burned violently. The flame spread from both sides of the sample to the two measuring points on the back of the burning surface of the sample, so the temperature rise rate of TC 7 and TC 9 was accelerated. When the fire time reached $850 \mathrm{~s}$, the temperature of the points other than TC 1 and TC 5 tended to be stable, and the temperature rise rate began to become gentle. This is because the temperature of the wood at these points was mainly under the heat radiation of the fire source. The temperature slowly increased and finally stabilized below $100^{\circ} \mathrm{C}$. Because TC 1 and TC 5 were directly above the fire source, their temperature kept increasing under the action of heat radiation from the fire source. When the fire time reached $2760 \mathrm{~s}$, the TC 5 position of the partition board was burned through at this time, and the flame spread through the burnt-through part to the hot spot at the point on the back of the sample, causing the temperature of the TC 5 to rise rapidly.

According to Figure 7, when the fire time reached 1985 s, the temperature of TC 6 increased rapidly and then decreased rapidly. At this time, the temperature rise of other measuring points was not obvious. According to the observed field test phenomenon, the sample at this moment burned violently under the action of the fire source, and the flame spread along one side of the sample to the thermocouple at TC 6 on the back of the sample. 
After a period of time, the flame was gradually extinguished, so the temperature of TC 6 first rose and then fell. When the fire time reached $3200 \mathrm{~s}$, the temperature of TC 1 and TC 3 began to rise, and the temperature of other points showed a downward trend. Because the sample was not fully burned, the temperature of TC 1 and TC 3 continued to rise under the heating of the fire source, and the temperature of the other points was stabilized below $100{ }^{\circ} \mathrm{C}$ under the heat radiation of the fire source. When the fire time reached $5700 \mathrm{~s}$, and the sample burned through at the position of TC 1 . When the sample was exposed to fire for $5725 \mathrm{~s}$, the temperature of TC 3 rose rapidly, and the wood sample between TC 1 and TC 3 burned through. During the test, it was found that the partition board sample A-20 burned through $45 \mathrm{~min}$ after being fired. The partition board sample A-25 was burned through $95 \mathrm{~min}$ after being fired. Therefore, when the thickness of the sample section increased by $5 \mathrm{~mm}$ under the same fire source, its fire resistance time was doubled, and the final temperature of each measuring point of the sample was not much different.

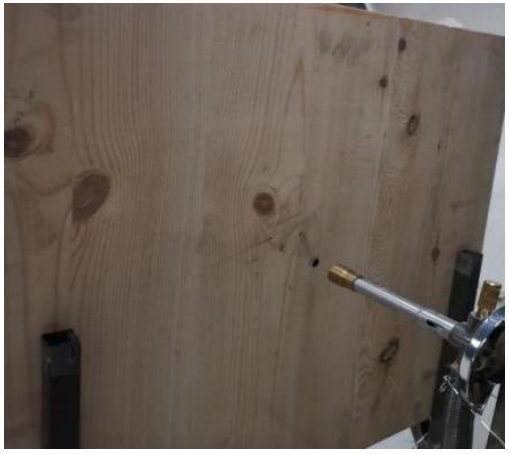

(a)

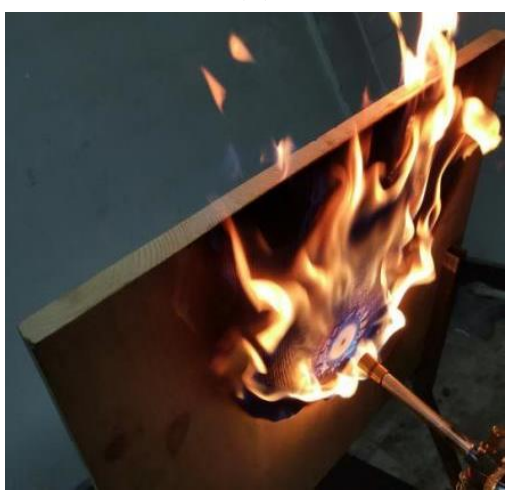

(c)

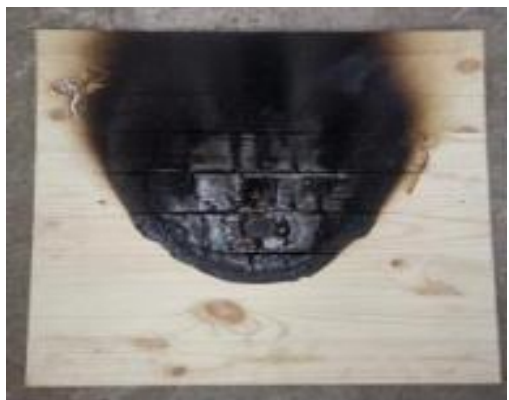

(e)

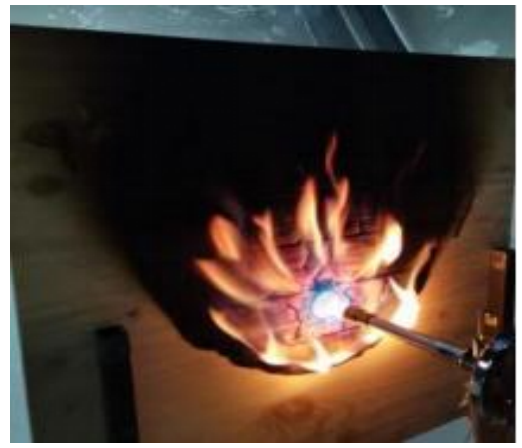

(b)

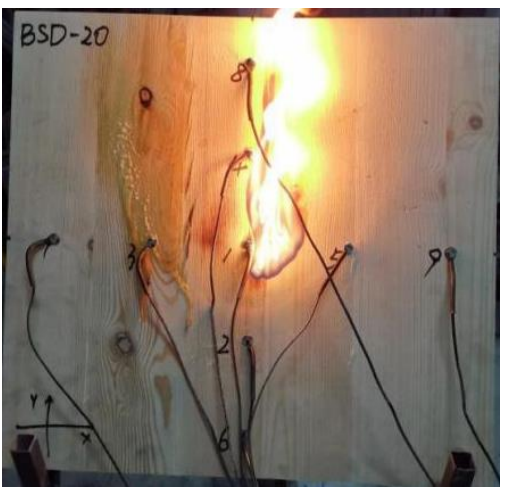

(d)

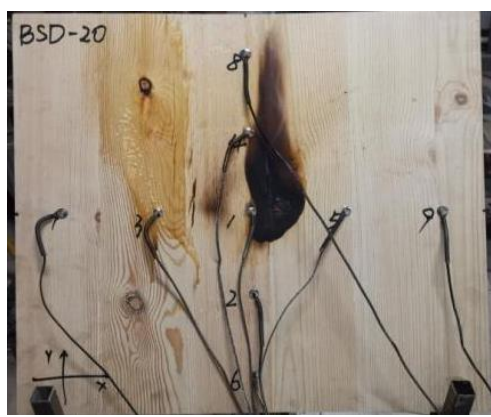

(f)

Figure 5. Combustion of sample B-20. (a) 0 s; (b) 500 s; (c) 800 s; (d) 1200 s; (e) End of the trial by fire wood surface; (f) End of the test on the back of the board. 


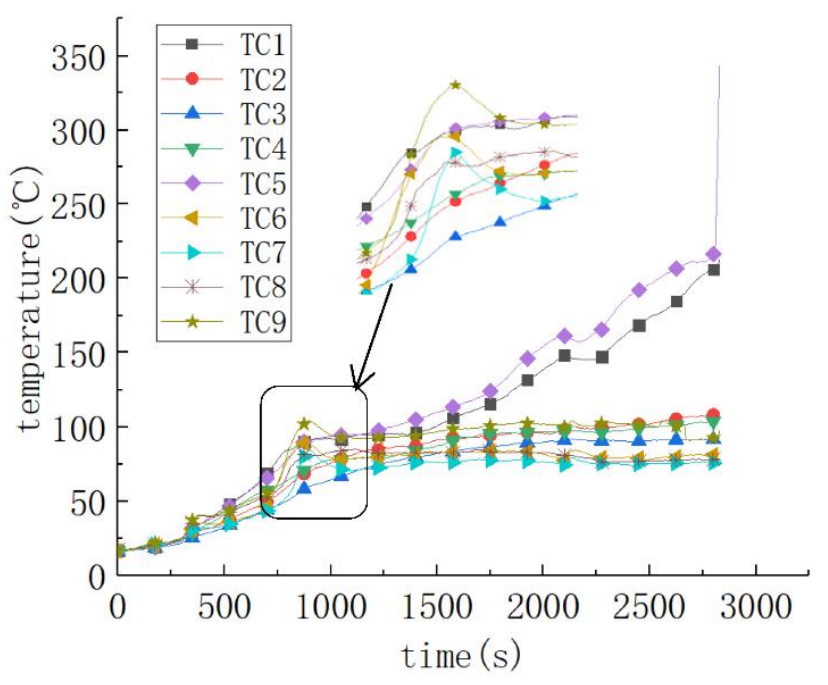

Figure 6. Temporal evolution of sample A-20's temperature.

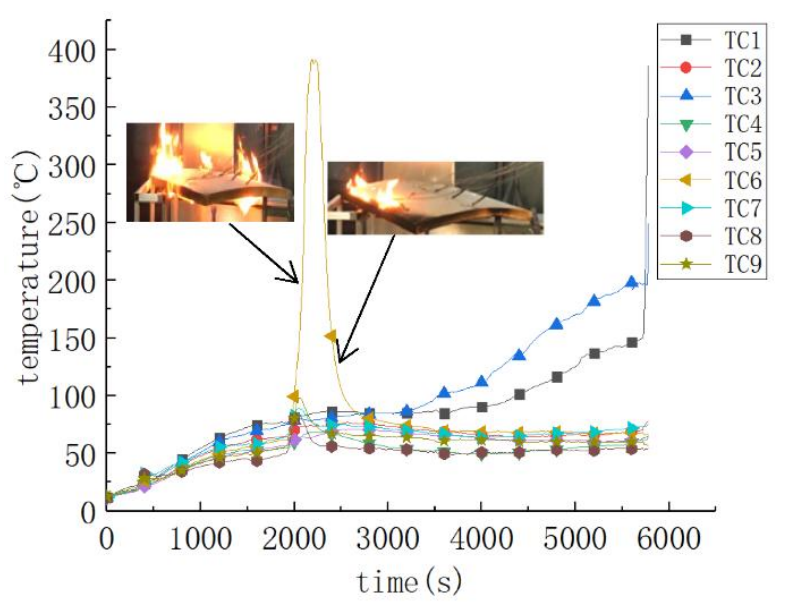

Figure 7. Temporal evolution of sample A-25's temperature.

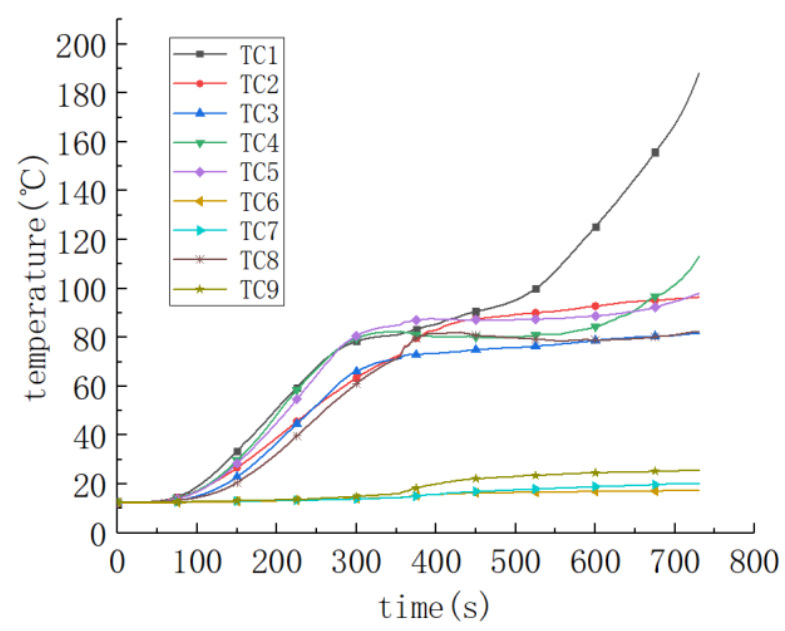

Figure 8. Temporal evolution of sample B-15's temperature. 


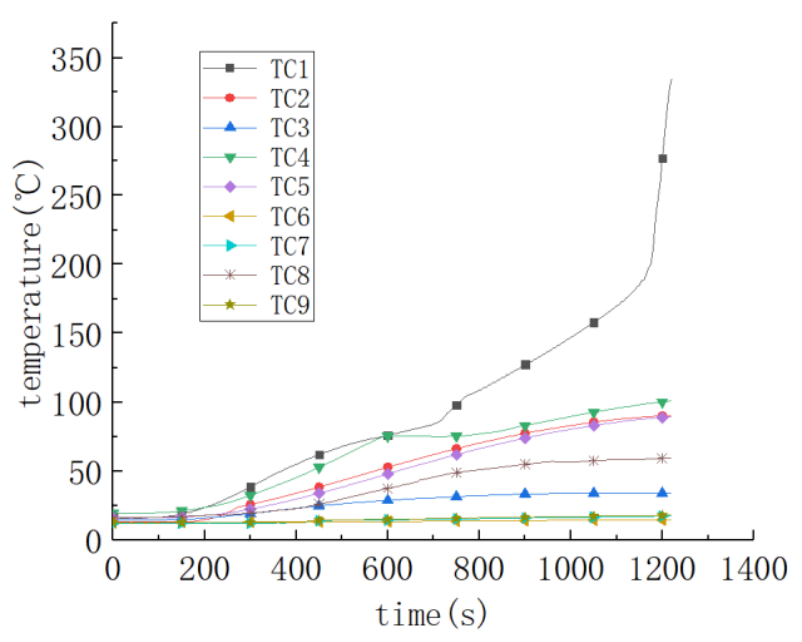

Figure 9. Temporal evolution of sample B-20's temperature.

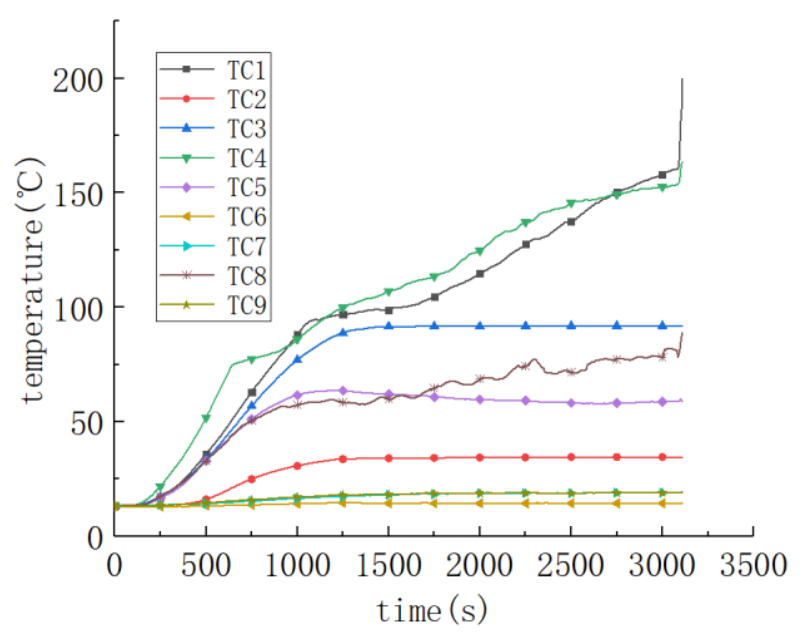

Figure 10. Temporal evolution of sample B-25's temperature.

According to Figure 8, before the test time reached $300 \mathrm{~s}$, the temperature of other measuring points except TC 6 , TC 7, and TC 9 continued to rise. This is because the Bunsen burner flame was more concentrated. The sample area was small, and the flame did not radiate to the location where the TC 6, TC 7, and TC 9 were located on the sample, so the temperature of three measurement points was basically unchanged. After the sample was exposed to fire for $350 \mathrm{~s}$, the temperature rise rates of TC 2, TC 3, TC 4, TC 5, and TC 8 were decreased. When the sample was exposed to fire for $650 \mathrm{~s}$, the temperature of the center of the sample increased with the time of fire, and the thickness of the sample section continued to decrease. Due to the thermal radiation of the flame, the temperature of TC 1 and TC 4 rose rapidly. When the sample was exposed to fire for $720 \mathrm{~s}$, TC 1 was burned through.

According to Figure 9, when the fire time of the sample reached $1200 \mathrm{~s}$, the location of TC 1 was burned through, and the temperature of TC 1 rose rapidly. The burn-through time of sample B-20 was 480 s longer than that of sample B-15.

According to Figure 10, the temperature of TC 1 and TC 4 began to rise rapidly. When the sample was exposed to fire for $3120 \mathrm{~s}$, and the center of the sample was burned through at this time. The burn-through time of sample B-25 was $2400 \mathrm{~s}$ longer than that of sample B-15 and $1920 \mathrm{~s}$ longer than that of sample B-20. The final temperature of other measuring points on sample B-25 was higher than that of sample B-15 and sample B-20. This is because the increase in the thickness of the sample led to a prolonged time of exposure to fire, and 
the temperature of the fire source acted on other measuring points through heat conduction, causing its temperature to rise.

In combination with Figure 5, Figure 8, Figure 9, Figure 10, it can be seen that the fire source area of the methane Bunsen burner was small, but the temperature was very high. Therefore, the burning time of the partition board sample at the center of the flame was faster in the fire test. Compared with the test specimen with the same section thickness, the burning time of the test specimen under the action of the pool fire was shortened by half. However, the burning damage of the fire surface in the test was mainly located at the center of the flame and above the flame. Increasing the thickness of the sample can improve the fire resistance of the sample. The average temperature at each measuring point of the thicker sample was higher than that of the thinner sample.

\subsection{Analysis of Sample Carbonization}

In the combustion process of partition board, the heat from the flame was received and absorbed by the combustible board via three typical forms including heat radiation, heat convection, and heat conduction. As a result, the temperature of the board increased up to its pyrolysis temperature, and the combustible gases were pyrolyzed out continuously. Further, with the sustained exposure of wood to fire, the temperature of the board surface increased and the temperature difference of between the surface and the internal board became smaller. Furthermore, the temperature difference reduced with the increase of distance from the fire source.

In the pool fire combustion test of the partition board sample, in order to understand the wood carbonization thickness and average carbonization rate at each measurement point of the sample during the combustion process, the sample was taken out after the test. The board was cut off at the place of each measuring point, the thickness of the carbonized part was measured, and the carbonization rate was obtained by dividing the carbonization thickness by the total thickness. The duration of sample A-20 was $46 \mathrm{~min}$, that of sample A-25 was $95 \mathrm{~min}$, that of sample B-15 was $12 \mathrm{~min}$, that of sample B-20 is $20 \mathrm{~min}$, and that of sample B- 25 was $52 \mathrm{~min}$. The duration means the consumed time that it takes for the sample to be burnt through at the center under the heating effect by the fire source. The formula for calculating the carbonization rate is shown in Equation (1). The calculation method of average carbonization speed at each measuring point is shown in Equation (2). Table 2 shows the initial thickness, remaining thickness, carbonization rate, and average carbonization speed of each sample at different measuring points. According to the information in Table 2, it can be seen that the carbonization rate and average carbonization speed of the measurement points farther from the center point were smaller. Under the action of the same fire source, the sample with a smaller thickness had a faster average carbonization rate at its center point. The comparison of the carbonization rate at each point of the sample is shown in Figure 11. In Figure 11, the abscissa represents the location of the measuring points, and the ordinate represents the carbonization rate at each measuring point. The carbonization rates of the horizontal thermocouples including TC 1, TC 2, TC 4, TC 6, and TC 8 are listed in Figure 11a,c, in which the abscissa of " 0 " represents TC 1, " 100 " represents TC 4 point, "200" represents TC 8, " -100 " represents TC 2 , and " -200 " represents TC 6 . The carbonization rate of vertical thermocouples including TC 1, TC 3, TC 5, TC 7, and TC 9 is listed in Figure 11b,d, in which " 0 " represents TC 1, " 100 " represents TC 3, "200" represents TC 7, "-100" represents TC 5, and " $-200 "$ represents TC 9.

$$
\begin{aligned}
& C=\frac{I-R}{I} \\
& S=\frac{I-R}{T}
\end{aligned}
$$




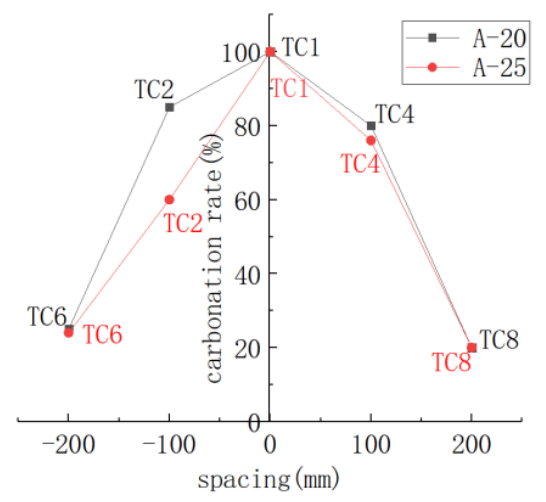

(a)

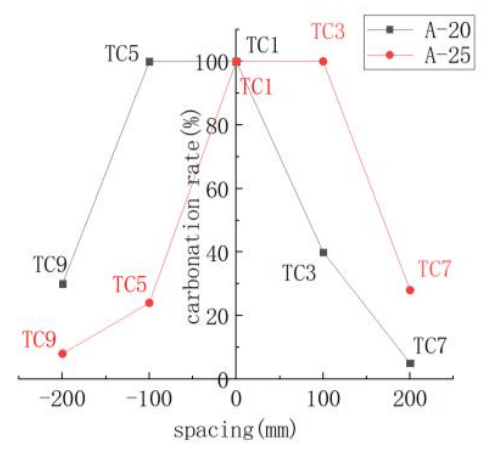

(b)

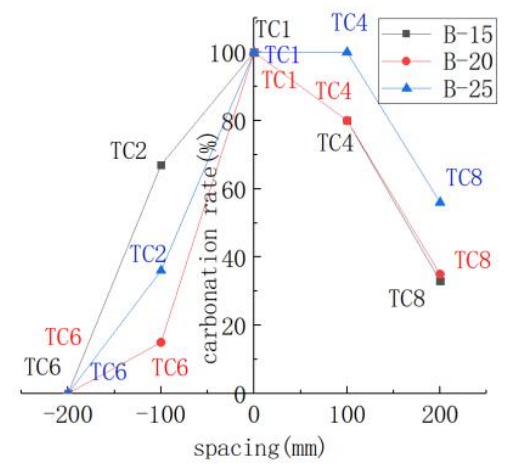

(c)

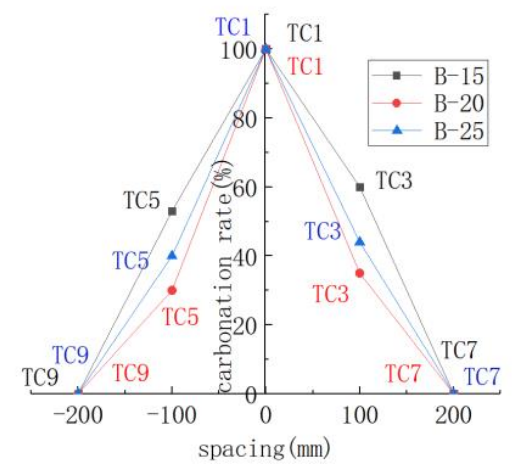

(d)

Figure 11. Comparison of the carbonization rate of each measuring point of the sample. (a) Carbonization rate at 5 points on the abscissa of sample A; (b) Carbonization rate at 5 points on the ordinate of sample A; (c) Carbonization rate at 5 points on the abscissa of sample B; (d) Carbonization rate at 5 points on the ordinate of sample $B$. 
Table 2. Parameters at each measuring point of the sample.

\begin{tabular}{|c|c|c|c|c|c|c|c|c|c|c|}
\hline Name & Parameter & TC1 & TC2 & TC3 & TC4 & TC5 & TC6 & TC7 & TC8 & TC9 \\
\hline \multirow{4}{*}{ Sample A-20 } & $I(\mathrm{~mm})$ & & & & & 20 & & & & \\
\hline & $R(\mathrm{~mm})$ & 0 & 3 & 12 & 4 & 0 & 15 & 19 & 16 & 14 \\
\hline & $C(\%)$ & 100 & 85 & 40 & 80 & 100 & 25 & 5 & 20 & 30 \\
\hline & $S(\mathrm{~mm} / \mathrm{min})$ & 0.435 & 0.37 & 0.174 & 0.348 & 0.435 & 0.109 & 0.022 & 0.087 & 0.13 \\
\hline \multirow{4}{*}{ Sample A-25 } & $I(\mathrm{~mm})$ & & & & & 25 & & & & \\
\hline & $R(\mathrm{~mm})$ & 0 & 10 & 0 & 6 & 19 & 19 & 18 & 20 & 23 \\
\hline & $C(\%)$ & 100 & 60 & 100 & 76 & 24 & 24 & 28 & 20 & 8 \\
\hline & $S(\mathrm{~mm} / \mathrm{min})$ & 0.263 & 0.158 & 0.263 & 0.2 & 0.063 & 0.063 & 0.074 & 0.053 & 0.021 \\
\hline \multirow{4}{*}{ Sample B-15 } & $I(\mathrm{~mm})$ & & & & & 15 & & & & \\
\hline & $R(\mathrm{~mm})$ & 0 & 5 & 6 & 3 & 7 & 15 & 15 & 10 & 15 \\
\hline & $C(\%)$ & 100 & 67 & 60 & 80 & 53 & 0 & 0 & 33 & 0 \\
\hline & $S(\mathrm{~mm} / \mathrm{min})$ & 1.25 & 0.83 & 0.75 & 1 & 0.667 & 0 & 0 & 0.417 & 0 \\
\hline \multirow{4}{*}{ Sample B-20 } & $I(\mathrm{~mm})$ & & & & & 20 & & & & \\
\hline & $R(\mathrm{~mm})$ & 0 & 17 & 13 & 4 & 14 & 20 & 20 & 13 & 20 \\
\hline & $C(\%)$ & 100 & 15 & 35 & 80 & 30 & 0 & 0 & 35 & 0 \\
\hline & $S(\mathrm{~mm} / \mathrm{min})$ & 1 & 0.15 & 0.35 & 0.8 & 0.3 & 0 & 0 & 0.35 & 0 \\
\hline \multirow{4}{*}{ Sample B-25 } & $I(\mathrm{~mm})$ & & & & & 25 & & & & \\
\hline & $R(\mathrm{~mm})$ & 0 & 16 & 14 & 0 & 15 & 25 & 25 & 11 & 25 \\
\hline & $C(\%)$ & 100 & 36 & 44 & 100 & 40 & 0 & 0 & 56 & 0 \\
\hline & $S(\mathrm{~mm} / \mathrm{min})$ & 0.481 & 0.173 & 0.211 & 0.481 & 0.192 & 0 & 0 & 0.269 & 0 \\
\hline
\end{tabular}

In which, $I$ is the initial thickness, $R$ is the remaining thickness, $C$ is the carbonization rate, $T$ is the test time, $S$ is the average carbonization speed.

According to the situation shown in Table 2 and Figure 11, it can be seen that under the same pool fire heating condition for samples with different cross-section thickness, the carbonization rate of the samples with small cross-section thickness was higher than that of the samples with large cross-section thickness. The maximum average carbonization speed of each measuring point of sample A-20 was $0.435 \mathrm{~mm} / \mathrm{min}$. The maximum average carbonization speed of each measuring point of sample A-25 was $0.263 \mathrm{~mm} / \mathrm{min}$. The maximum average carbonization rate of sample A-25 was $60 \%$ of that of sample A-20. The burn-through time of sample A-25 was $95 \mathrm{~min}$, and the burn-through time of sample A-20 was $46 \mathrm{~min}$. The cross-section thickness of sample A- 25 was $5 \mathrm{~mm}$ more than that of sample A-20, and the thickness increased by $25 \%$, and the fire resistance time doubled. The closer the location of each measuring point to the center of the fire source, the more serious the carbonization and the greater the carbonization rate.

Under the heating condition of the methane Bunsen burner, the smaller the remaining thickness at each measuring point of the sample, the greater the carbonization rate of the sample. The maximum average carbonization speed of each measuring point of sample B15 was $1.25 \mathrm{~mm} / \mathrm{min}$ at TC 1 , the maximum average carbonization speed of each measuring point of sample B-20 was $1 \mathrm{~mm} / \mathrm{min}$ at TC 1 , and the maximum average carbonization speed of each measuring point of sample B- 25 was $0.481 \mathrm{~mm} / \mathrm{min}$ at TC 1 and TC 4 . Except TC 1 , the maximum carbonization rate of sample B- 15 and sample B-20 was $80 \%$, and the maximum carbonization rate of sample B-25 was 100\%, which means that as the thickness of the sample increased, the fire resistance time of the samples increased. Through the heat conduction of the wood and the heating effect of the fire source, TC 4 of the B-25 specimen was burned through. For TC 6, TC 7, and TC 9 of the three samples under the Bunsen burner fire source, due to the methane Bunsen burner flame and the position of the sample, the three measurement points did not burn, so the carbonization rate was zero. The burn-through time of sample B-25 under the heating condition of methane Bunsen burner was $52 \mathrm{~min}$, which is $160 \%$ more than that of sample B-20, and $333 \%$ more than that of sample B-15. From this, we know that increasing the thickness of the sample improved the fire resistance of the sample. The change trend of carbonization rate at five points on the abscissa of sample A was the same, and the change trend of carbonization rate at five points on the ordinate showed symmetry about the $X$ axis. Each measuring point of the 
sample was centered on TC 1 and was symmetrical on both sides, so it can be considered that the change trend of carbonization rate at five points was same. The change trend of the carbonization rate of the test point of sample B was same on the abscissa and ordinate.

\section{Conclusions}

In this paper, we designed the experiment of heating different thickness of partition wall wood samples by pool fire and Bunsen burner. Through the test, the test phenomenon, the temperature change of the sample, and the carbonization rate of the sample were obtained, and the influence of the pool fire and the Bunsen burner fire source on the partition wall boards of different thicknesses was analyzed. The conclusions are as follows:

1. Through the Bunsen burner test, the thickness of the sample cross-section increased by $5 \mathrm{~mm}$, the time required for the sample to burn through showed a geometric increase, and the average carbonization speed at the center of the sample decreased exponentially.

2. When a sample of the same size was burned under the Bunsen burner fire source compared with the pool fire source, the burn-through time of the center point of the sample was shorter, and the carbonization rate and the average carbonization speed were greater. Therefore, relevant measures must be taken to solve the problem of excessive concentration of fire sources when a fire accident occurs.

Author Contributions: Conceptualization, B.G. and S.W.; test, B.G. and H.Y.; formal analysis, B.G.; survey, Y.C.; data management, B.G. and H.Y.; writing - manuscript preparation, B.G.; writingreview and editing, S.W. and W.D.; visualization, W.D.; supervision, S.W.; project management, S.W. All authors have read and agreed to the published version of the manuscript.

Funding: This research was funded by Guizhou Province Science and Technology Support Project (Qiankehe Support [2019] 2889 \& [2020] 4Y055).

Conflicts of Interest: The authors declare no conflict of interest.

\section{References}

1. Lau, P.W.C.; White, R.; Zeeland, I.V. Modelling the charring behaviour of structural lumber. Fire Mater. 1999, 23, 209-216. [CrossRef]

2. Spearpoint, M.J.; Quintiere, J.G. Predicting the burning of wood using an integral model. Combust Flame 2000, 123, 308-325. [CrossRef]

3. Frangi, A.; Fontana, M. Charring rates and temperature profile of wood sections. Fire Mater. 2003, 27, 91-102. [CrossRef]

4. Janssens, M. Modeling of the thermal degradation of structural wood members exposed to fire. Fire Mater. 2004, 28 , 199-207. [CrossRef]

5. Van Zeeland, I.M.; Salinas, J.J.; Mehaffey, J.R. Compressive strength of lumber at high temperatures. Fire Mater. 2005, 29, 71-90. [CrossRef]

6. Hofmann, V.; Gräfe, M.; Werther, N.; Winter, S. Fire resistance of primary beam-secondary beam connections in timber structures. J. Struct. Fire Eng. 2016, 7, 126-141. [CrossRef]

7. König, J. Effective thermal actions and thermal properties of timber members in natural fires. Fire Mater. 2006, 30, 51-63. [CrossRef]

8. Thomas, G. Fire Resistance and Burnout Resistance of Timber Columns. Fire Saf. J. 2021, 122, 103350.

9. Zhang, Z.; He, Z.; Xu, Z.; Chen, L. Calculating moisture emissivity of timber members with different surface treatment. Constr. Build. Mater. 2021, 269, 121253. [CrossRef]

10. Kačíková, D.; Kubovský, I.; Ulbriková, N.; Kačík, F. The Impact of Thermal Treatment on Structural Changes of Teak and Iroko Wood Lignins. Appl. Sci. 2020, 10, 5021. [CrossRef]

11. White, R.H.; Nordheim, E.V. Charring rare of wood for ASTM E119 exposure. Fire Technol. 1992, 28, 5-30. [CrossRef]

12. Schnabl, S.; Turk, G.; Planinc, I. Buckling of timber columns exposed to fire. Fire Saf. J. 2011, 46, 431-439. [CrossRef]

13. Ali, F.; Kavanagh, S. Fire resistance of timber columns. J. Inst. Wood Sci. 2005, 17, 85-93. [CrossRef]

14. Park, J.S. Fire Performance of Laminated Veneer Lumber (LVL) with Glued-in Steel Rod Connections. J. Fire Sci. 2006, 24, 27-46. [CrossRef]

15. Frangi, A.; Fontana, M.; Hugi, E.; Jübstl, R. Experimental analysis of cross-laminated timber panels in fire. Fire Saf. J. 2009, 44, 1078-1087. [CrossRef]

16. Babrauskas, V. Charring Rate of Wood as a Tool for Fire Investigations. Fire Saf. J. 2005, 40, 528-554. [CrossRef]

17. Blondin, F.; Blanchet, P.; Dagenais, C.; Triantafyllidis, Z.; Bisby, L. Fire hazard of compressed straw as an insulation material for wooden structures. Fire Mater. 2020, 44, 736-746. [CrossRef] 
18. Rabe, S.; Klack, P.; Bahr, H.; Schartel, B. Assessing the fire behavior of woods modified by N-methylol crosslinking, thermal treatment, and acetylation. Fire Mater. 2020, 44, 530-539. [CrossRef]

19. Suoware, T.; Edelugo, S.; Ezema, I. Impact of hybrid flame retardant on the flammability and thermomechanical properties of wood sawdust polymer composite panel. Fire Mater. 2019, 43, 335-343. [CrossRef]

20. Wang, F.; Liu, J.; Lv, W. Thermal degradation and fire performance of wood treated with PMUF resin and boron compounds. Fire Mater. 2017, 41, 1051-1057. [CrossRef]

21. Hirschler, M. Poly(vinyl chloride) and its fire properties. Fire Mater. 2017, 41, 993-1006. [CrossRef]

22. He, X.; Li, X.; Zhong, Z.; Mou, Q.; Yan, Y.; Chen, H.; Liu, L. Effectiveness of impregnation of ammonium polyphosphate fire retardant in poplar wood using microwave heating. Fire Mater. 2016, 40, 818-825. [CrossRef]

23. Audouin, L.; Kolb, G.; Torero, J.L.; Most, J.M. Average centreline temperatures of a buoyant pool fire obtained by image processing of video recordings. Fire Saf. J. 1995, 24, 167-184. [CrossRef]

24. Koseki, H. Estimation of Thermal Balance in Heptane Pool Fire. J. Fire Sci. 1989, 7, 237-250. [CrossRef]

25. Hamins, A.; Fischer, J.; Kashiwagi, T.; Klassen, M.E.; Gore, J.P. Heat Feedback to the Fuel Surface in Pool Fires. Combust. Sci. Technol. 1994, 97, 37-62. [CrossRef]

26. Chatris, J.M.; Quintela, J.; Folch, J.; Planas, E.; Arnaldos, J.; Casal, J. Experimental study of burning rate in hydrocarbon pool fires. Combust. Flame 2001, 126, 1373-1383. [CrossRef]

27. Kang, Q.; Lu, S.; Chen, B. Experimental study on burning rate of small scale heptane pool fires. Chin. Sci. Bull. 2010, 55, 973-979. (In Chinese) [CrossRef]

28. Hörold, S. Phosphorus flame retardants in thermoset resins. Polym. Degrad. Stab. 1999, 64, 427-431. [CrossRef]

29. Morgan, A. Flame retarded polymer layered silicate nanocomposites: A review of commercial and open literature systems. Polym. Degrad. Stab. 2006, 17, 206-217. [CrossRef]

30. Plyler, E.K. Infra-red radiation from a Bunsen burner. J. Opt. Soc. Am. 1947, 37, 984.

31. Kozlovsky, G.; Sivashinsky, G.I. On open and closed tips of bunsen burner flames. Theor. Comput. Fluid Dyn. 1994, 6, 191-192. [CrossRef]

32. Zhang, Y.; Liang, X.; Wang, X. Study on the critical parameters of oil pool fire with different sizes. Fire Sci. Technol. 2018, 37, 306-309.

33. HB 6167.14-2014 "Environmental Conditions and Test Procedures for Airborne Equipment of Civil Airplane-Part 14: Fire Flammability Test". Available online: https://www.miit.gov.cn/datainfo/zysjk/bzgf/art/2020/art_5a0d8504976046d68055c2b6 5a620e5c.html (accessed on 20 June 2021).

34. Peng, L.; Qiu, P.; Cui, H.; Yuan, L. Experimental study on charring of crossliaminated timber exposed to standard fire. Fire Sci. Technol. 2020, 39, 1499-1503. 